\title{
Children's self-report of pain intensity: What we know, where we are headed
}

\author{
Carl L von Baeyer PhD RDPsych
}

CL von Baeyer. Children's self-report of pain intensity: What we know, where we are headed. Pain Res Manage 2009;14(1):39-45.

The present paper provides a short, practical introduction to children's self-report measures of pain intensity, followed by an overview of principles and issues. Details on individual self-report scales were previously reported in a landmark systematic review in 2006 and will not be repeated here. Broader measurement issues discussed here include interpretation of pain scores over time, across individuals and in relation to contextual factors; special considerations affecting children younger than six years of age; social communicative functions of pain reports; cognitive developmental factors in understanding pain scales and their anchors; screening for the ability to use self-report scales and training for children who do not have this skill; level of measurement (interval versus ordinal); estimating clinically significant change for groups and individuals; and measurement of aspects of pain other than intensity. Also highlighted are areas in which there has been progress and a lack of progress since the last time this topic was featured at the International Forum on Pediatric Pain in 1996. The present article closes with an outline of key areas for further research on children's self-report of pain and a brief summary of recommendations for clinicians.

Key Words: Child; Faces scales; Measurement; Numerical rating scale; Pain intensity; Pain scale; Self-report

\section{OVERVIEW OF SELF-REPORT MEASUREMENT}

The management of pain may be improved by the measurement of its intensity $(1,2)$. For example, analgesic doses can be adjusted to reports of pain intensity. Most children older than four years of age are able to provide estimates of their pain intensity using developmentally appropriate scales (Figure 1). Because pain is primarily a subjective experience, self-report measures are considered primary, if not a gold standard $(3,4)$, and should be obtained when possible. When self-reports are unavailable or in doubt, observational measures can be used as a complement or substitute. Recent reviews of self-report (5) and observational $(4,6)$ scales provide details and references for these measures, which need not be repeated here. Practical considerations in selection and interpretation of pediatric selfreport pain scales are also discussed elsewhere (7).

Older children and adolescents can use visual analogue scales (VAS), adjective descriptor scales and numerical rating scales (NRS), as applied with adult patients. Children younger than seven or eight years of age prefer and do better with faces scales $(8,9)$. Many are available, including the Faces Pain Scale - Revised (FPS-R) (10; www.painsourcebook.ca), the Wong-Baker FACES Pain Rating Scale (11) and the Oucher (12). Self-report methods are not well established for three- and

\section{L'autoévaluation de l'intensité de la douleur par les enfants : Ce que l'on sait, vers où l'on va}

Le présent article présente une courte introduction pratique aux mesures d'autoévaluation de l'intensité de la douleur par les enfants, suivie d'un aperçu des principes et des enjeux. Les détails des diverses échelles d'autoévaluation figurent dans une analyse systématique qui a fait autorité et qui n'est pas reprise aux présentes. Les enjeux plus vastes reliés aux mesures abordées dans le présent article sont l'interprétation des indices de la douleur au fil du temps, entre individus et par rapport à des facteurs contextuels, des facteurs spéciaux reliés aux enfants de moins de six ans, les fonctions communicatives sociales des rapports sur la douleur, les facteurs de développement cognitif pour comprendre les échelles de la douleur et leurs points d'ancrage, le dépistage de la capacité d'utiliser les échelles d'autoévaluation et la formation des enfants qui ne possèdent pas ces capacités, le taux de mesure (par intervalle plutôt que par paramètres ordinaux), l'évaluation de changements cliniquement significatifs selon les groupes et les individus et la mesure d'autres aspects de la douleur que l'intensité. On souligne aussi les secteurs où on a constaté des progrès et l'absence de progrès depuis les dernières présentations sur le sujet, à l'International Forum on Pediatric Pain, en 1996. L'article se termine par un aperçu des principaux secteurs où il faut approfondir les recherches sur les autoévaluations de la douleur par les enfants et par un résumé des recommandations aux cliniciens.

four-year-olds, although some can use the Pieces of Hurt tool (13) and faces scales (9).

In applying and researching self-report measures of pain, there are many interesting theoretical and practical issues to take into account.

\section{MEASUREMENT ISSUES}

\section{A necessary oversimplification}

Reducing the experience of pain to a single number reflecting intensity is a gross oversimplification. It may be compared with trying to describe music using only a scale of loudness. Pain has many characteristics in addition to its intensity - location, sensory qualities, cognitive appraisal and affective reactions, among others. However, pain intensity scores are needed, at least in research and clinical trials, if not in clinical practice (14), to inform, evaluate and improve pain management. Thus, pain scores may be considered a necessary oversimplification.

\section{Comparisons over time versus between individuals}

In general, pain intensity scores are much more useful for comparisons over time within individuals, rather than comparisons between individuals. Consider the example of two hypothetical children who rate their pain during their recovery from the

Departments of Psychology and Pediatrics, University of Saskatchewan, Saskatoon, Saskatchewan

Correspondence: Dr Carl L von Baeyer, Department of Psychology, University of Saskatchewan, 9 Campus Drive, Saskatoon, Saskatchewan

S7N 5A5. Telephone 306-966-6676,fax 306-966-6630, e-mail carl.vonbaeyer@usask.ca 


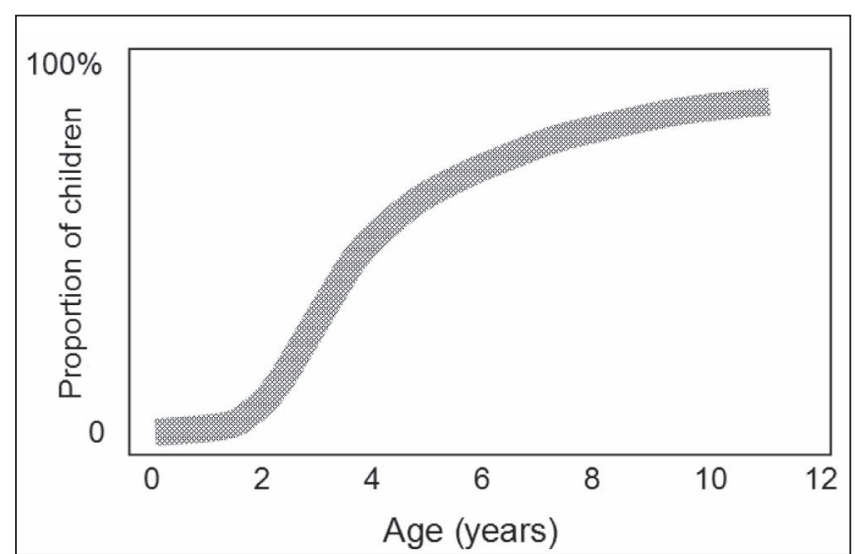

Figure 1) An estimate of the proportion of children at different ages who are able to provide a reliable self-report of pain when given an age-appropriate scale under optimal conditions. From reference 50. Copyright CL von Baeyer, 2003

same surgical operation. One provides an initial rating of $10 / 10$, the other a rating of $7 / 10$ (Figure 2). It cannot be assumed that the first child has more intense pain; the difference may be due to differences in the understanding of the pain scale or the interpretation of the top anchor of the scale. However, if each child shows a reduction in pain scores over time and following intervention, then pain management efforts are on the right track. An increase in pain score would trigger more active pain management, such as an increase in analgesic dose or addition of a nonpharmacological intervention.

\section{Social influences}

Self-reports of pain must be regarded as social communications, and as such, they are influenced by many developmental and social factors $(15,16)$. Self-reported pain intensity depends on who is asking, and the expected consequences of lower or higher pain reports. For example, a child who expects (realistically or not) to get another needle if she admits to postoperative pain is likely to give the nurse a low score. On the other hand, a child who wants to stay home from school and believes that he will be allowed to stay home if he complains of pain may provide the parent with an exaggerated report of his stomach ache. Thus, children's self-reports should be tempered with knowledge of the social context, and the child's likely motivations and expectations. However, no methods have been developed at this time to integrate self-reports with observer estimates of pain intensity; there has been a tendency to assume that one or the other has to be correct, whereas it may be more appropriate to consider that self- and observer reports are measuring separate constructs and that both should be obtained when possible (17).

\section{Cognitive influences}

In addition, children's understanding of self-report scales changes dramatically over time, particularly from three to seven years of age (Figure 1). The tendency of young children to use the bottom and top extremes rather than the middle of rating scales is well known $(10,18)$. Other frequent cognitive biases in preschool-age childrens' use of pain scales, such as the tendency to give consecutive ratings in a left-right or right-left order, have also recently been identified (19). These response

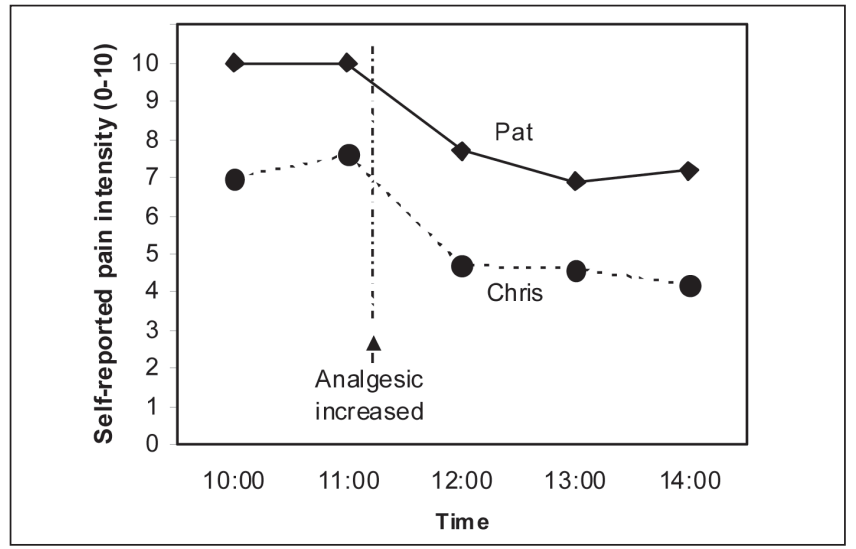

Figure 2) Pain trajectories for two hypothetical postsurgical patients. One cannot conclude that Pat is experiencing more pain than Chris, but the increase in analgesia appears to be helping both patients. From reference 7. Copyright CL von Baeyer, 2005

biases may serve to simplify rating tasks that are too complex for young children to answer readily.

\section{Anchor effects}

Anchor effects may be a major influence on pain ratings. With regard to the lower (no-pain) anchor on faces scales, Chambers and Craig (20) have demonstrated effects of using smiling versus neutral anchor faces. Scales that start with a smile produce higher pain scores than scales that start with a neutral face. For example, on the Wong-Baker FACES Pain Rating Scale, the lowest scoring face that shows any expression of distress is rated $6 / 10$. Older children readily discern the intent or the underlying dimensional nature of the scale; that is, they understand that the faces for scores 2 and 4 are intended to indicate low and moderate pain, respectively, although they show no distress. Young children, however, do not have the advantage of experience with scaling and magnitude estimation. The main rationale (9) for using faces scales (rather than VAS and NRS) is that faces scales do not require magnitude estimation or seriation, which are cognitive skills that most children do not encounter before entering school.

The effects of the upper anchor are more complex and less well studied. Many different anchor phrases have been used. Some of these require patients to rate their pain in relation to a hypothetical maximal pain state ('the most pain possible' or 'the most pain you can imagine' or the 'biggest hurt you could ever have'). There is no research on what children at different ages think when they hear or see such a phrase; presumably, some children think of pain states they have only heard of, such as being burned alive, while others think about the particular pain they have just experienced and remember most clearly. Other pain scales make no explicit reference to an imaginary maximal pain intensity, but use simpler phrases such as 'very much pain' or 'most pain.' It is likely that such differences in upper anchors have important effects on the magnitude of pain ratings, but this may not be an issue if the same scale is used consistently.

\section{Clinically significant change}

How large a difference between pain scores is clinically significant (21)? A few studies with children $(22,23)$ have addressed 
this question and have identified a minimum clinically significant difference (MCSD). Estimates of the MCSD depend on the type of pain, the starting pain level and other factors, but they tend to range from $10 \%$ to $20 \%$ - in other words, a change of one face on the FPS-R, or a change of $1 \mathrm{~cm}$ to $2 \mathrm{~cm}$ on a $10 \mathrm{~cm}$ VAS would be the smallest meaningful change. However, what is not clear from these group-based studies is to what extent an MCSD derived from mean group differences applies to individuals. If a child's pain diminishes from $8 / 10$ to $6 / 10$ following intervention, does that represent a significant improvement or a treatment success? The size of a clinically significant change may differ among children, and no standardized methods have been developed to obtain this information or to integrate it with the obtained pain score. An alternative to the MCSD that has commonly been used in clinical trials is to define treatment success as a $30 \%$ or $50 \%$ reduction in pain $(24,25)$. With the $50 \%$ criterion, a reduction from $10 / 10$ to $5 / 10$, and a reduction from $2 / 10$ to $1 / 10$ are equally considered successes. For clinical use, one can ask a child what level of pain (on the selected scale) would be acceptable or much better; this can be formulated as a realistic treatment target.

\section{Level of measurement}

Are self-report pain intensity scores parametric or nonparametric? There is debate among pain researchers concerning whether pain scores possess at least interval quality measurement, or are simply categorical or ordinal values (26). Perhaps this depends on the child using the scale as much as it does on the scale itself. In other words, a pain scale may be explicitly designed to be interval quality (eg, the FPS-R [10]), but some children, especially younger ones, will report scores on the scale in an ordinal, categorical or even dichotomous fashion $(10,18)$. Researchers need to consider and justify their choice of parametric versus nonparametric statistical methods (eg, Spearman's rank correlation versus Pearson's correlation).

\section{Features other than intensity}

To assess the location, sensory and affective qualities, as well as other aspects, tools other than pain intensity scales must be used. For example, the Adolescent Pediatric Pain Tool (27), the Pediatric Pain Questionnaire (28) and the Eland Color Tool (29) incorporate a body diagram on which a patient can indicate areas of pain. For younger children, informal clinical interviews and parental reports have been the only sources of such information to date.

\section{PROGRESS SINCE 1996}

The last time self-report measurement was reviewed at the International Forum on Pediatric Pain was in 1996 by Champion et al (9). Since that time, there has been great progress in some areas and no progress in others.

\section{Pediatric Initiative on Methods, Measurement, and Pain} Assessment in Clinical Trials review

Perhaps the single most important development in pediatric self-report of pain intensity since the Champion et al (9) review was the publication of a major systematic review of self-report measures of pain intensity (5). This review was commissioned by the Pediatric Initiative on Methods, Measurement, and Pain Assessment in Clinical Trials
(PedIMMPACT, www.immpact.org), a collaboration intended to develop consensus reviews and recommendations for improving the design, execution and interpretation of clinical trials related to pediatric pain. The availability of this authoritative major review makes it unnecessary to list the many individual instruments that have been published.

\section{Common metric}

In the 1980s and 1990s, pain self-report measures still used a variety of metrics ( 0 to 4,0 to 5,0 to 6,1 to 7,0 to 10,0 to 100 and others). The author observed at one children's hospital that medical charts sometimes contained a pain rating without an indication of which of three scales on three different metrics was used to obtain the rating, making the score uninterpretable. An international survey on the pediatric pain e-mail listserv (www.pediatricpain.ca/professional/mailingList.html) revealed a strong preference for the 0 to 10 metric (30). Since then, the Faces Pain Scale was revised to create the FPS-R, which is scored on the 0 to 10 metric (10). The Wong-Baker FACES Pain Rating Scale has also been adapted to use the 0 to 10 metric, and that metric has been recommended in the United States (US) hospital accreditation guidelines (www. jointcommission.org) for general use.

\section{Sociocommunication model}

An important theoretical advance in understanding the nature of children's self-report of pain has come about with the creation of the sociocommunication model of pain by Craig (16), and Hadjistavropoulos and Craig (15). This model makes it clear that self-reports of pain, similar to nonverbal expressions of pain, are a form of social behaviour and are, therefore, subject to many triggering, modulating and reinforcing influences. Pain intensity cannot be measured in the sense that a thermometer measures temperature; it can only be estimated from different points of view. For example, even with tightly controlled experimental pain stimuli, the sensation, perception and report of pain are influenced by the presence and behaviour of observers, and by the subject's expectations. Thus, to maintain an appreciation of the richness and complexity of children's self-reports of pain intensity, it is essential to view them as social communications.

\section{Wide dissemination and adoption}

In the US, major impetus has been given to the use of children's self-report scales by the publication of Pain: Clinical Manual (31) by McCaffery and Pasero, and also by the movement spearheaded by nurses to consider pain to be the 'fifth vital sign'. In France, information about children's self-report scales has been widely disseminated on the Internet (eg, www.pediadol.org). International dissemination of information about pain assessment (32) has also occurred in other countries such as Thailand, Brazil, Jordan and China. Until the 1990s, many clinical trials of pediatric analgesics were published using only observational or informal measures. Inclusion of validated self-report scales wherever possible (eg, in children older than four years of age) is now much more common, as recommended in the PedIMMPACT reviews $(4,5)$.

\section{Electronic data collection}

Collection and recording of pain scores using electronic methods is a significant recent development (33). The use of a 
personal digital assistant has many advantages, not the least of which is that most children enjoy using the technology. The e-Ouch, or iDiary electronic diary, was developed for home use by children with arthritis (34), with good evidence of construct validity and feasibility (35). Groups in France and elsewhere are adapting the FPS-R and VAS for personal digital assistants (36). Computer-animated faces scales have been created independently by two groups $(10,37)$; their primary advantages may be momentary (real-time) electronic data collection, analysis and display; they have not yet been proven to have any psychometric advantage over simpler paper and pencil scales.

\section{LACK OF PROGRESS}

Lack of research on numerical rating scales

All VAS and faces scales require the use of physical materials (paper and pencil or mechanical devices), which require attention to infection control in institutional settings. By contrast, NRS require no physical materials, and can be administered in a rapid and purely verbal interaction between the caregiver and patient. There is some evidence that NRS are used more often than any other pain scale - certainly in adults (38) and possibly with children (30). Surprisingly, there is a gap in the literature with respect to the use of NRS in children. There is no standard wording or reliable information available about the youngest age for which NRS are appropriate. However, several very recent unpublished clinical studies (personal communication to author) have included NRS along with VAS and/or a faces scale, permitting validation efforts for NRS to commence. The results of these studies indicate that, for children nine years of age and older, NRS produce scores very similar to those of other psychometrically sound pain intensity measures. However, a lower age limit for NRS cannot be assessed using these studies; additional data are needed for children six to nine years of age to establish when most children are able to use NRS. It should be noted that the use of NRS requires not only the ability to count, but also the ability to estimate quantities in numerical terms, which is a more advanced developmental task that tends to be taught in school starting in approximately grade 3 .

\section{Lack of an ideal faces scale for young children}

Each of the existing faces scales has advantages and disadvantages. The Oucher (12) uses a vertical arrangement of faces, which is developmentally more appropriate than a side-to-side arrangement, and it is very well validated in clinical studies. However, it requires expensive colour printing and, therefore, presents infection control issues. Also, separate versions are required for each of many ethnic groups, and the comparability of these different versions with each other and with a theoretical ideal pain intensity dimension is not well established. The FPS-R has good psychometric qualities and its instructions are available in approximately 35 languages (www.painsourcebook.ca); it has been used in many clinical trials and has shown sensitivity to painful and pain-relieving conditions. However, although children seem to have no trouble with the FPS-R, the faces are not popular with adults (they have been characterized as 'Martian' and 'scary' by some adults). The Wong-Baker FACES Pain Rating Scale is subject to anchor effects as noted above; moreover, it is nonlinear and inherently multidimensional, ie, incorporating not only pain intensity but also affective cues of smiling and tears, and standard instructions referring to happiness. Finally, it has been shown that young children are more skilled in distinguishing the external features of objects than the internal details; however, all cartoon faces scales use the same sizes and shapes of faces. It would be developmentally more appropriate to vary the sizes of faces or alter the outline of the faces, not just the internal features of these depictions. None of the scales published to date are ideal.

\section{Measures for preschool-age children}

In a previous major review of pain assessment (9), we outlined special considerations applying to young children who have little or no school experience. Briefly, their cognitive and social development imposes limits on the complexity of feasible self-report measures. Getting valid information verbally from preschool children requires a relationship of trust that takes time to develop, and direct questions are rarely productive (39). Very few preschool children can understand VAS or NRS, and most children younger than four years of age have difficulty with the standard faces scales. The Pieces of Hurt tool (13) has been recommended for use with young children, but validation of the tool and its instructions for four-year-olds is very limited, and absent for three-year-olds.

\section{Response biases}

Young children will often respond using cognitive strategies that have little to do with the content of the question, making their responses idiosyncratic. Response biases such as a preference for the extremes serve to simplify questions that are otherwise too complex to understand (19). Well-validated and standardized methods for screening children for their ability to use self-report scales have yet to be developed (40). Asking children to sort objects by size (12) and to assign pain scores to hypothetical painful and nonpainful events (41) have been suggested as ways to screen children for their understanding of self-report scales.

\section{Context of measurement}

Knowledge of the context can and perhaps should influence the interpretation of pain scores. For example, many young children provide high pain scores before a painful procedure, probably communicating their distress or fear of pain rather than the pain actually experienced at that moment. An adult will find a child's high pain score more plausible after the procedure than before it. Similarly, a self-report of 0/10 obtained from a young child several hours after a major surgical operation generally known to be painful, in the absence of analgesia but the presence of nonverbal signs of distress, would be carefully considered. It may be appropriately disregarded by the clinician, whose duty may be to rely on observation and initiate appropriate pain management regardless of the self-report. A pain self-report of 0 , in this particular context, is more likely to be construed as indicating failure to understand the pain scale rather than insensitivity to or absence of pain. However, there are no established methods for integrating knowledge of context into pain intensity scores. Theoretically, it would be possible to adjust self-report scores upward or downward based on knowledge of the context, but in practice, it is more likely that self-reports discrepant with clinicians' knowledge of the context will simply be disregarded. 


\section{DIRECTIONS FOR RESEARCH}

\section{Theory-based studies}

In general, research on children's self-reports of pain has been pragmatic and atheoretical. Cognitive developmental theory has rarely been applied, except for frequent references to Piaget's stages of cognitive development, a theory that has been criticized since the 1980s. Hadjistavropoulos and Craig's sociocommunication model (15) provides many promising leads for theoretically driven research on self-report. Another theoretical viewpoint that bears promise is Vygotsky's theory (42), which integrates cognitive and social development. Vygotsky's description highlights how, over time, a child progresses from being unable to do a task, to being able to do the task with another person's support, suggestions and supervision, and eventually to being capable of completing the task independently. Finally, Wilkinson (39), in The Child's World of Illness, proposes the theoretical concept of 'ideal discourse', which is needed to get accurate information from young children. Each of these theoretical frameworks may provide an integrated conceptual basis for research on selfreport of pain.

\section{Does measurement improve outcome?}

Franck and Bruce (14) identified the inadequate evidence for improved pain management outcomes following structured pain assessment (both self-report and observational). Before making further efforts to impose the use of pain scales on reluctant practitioners, one should have better evidence that it actually makes a difference in outcome.

\section{Better faces scale}

In a symposium entitled "Putting a New Face on Faces Scales" at the 7th International Symposium on Pediatric Pain (43), there was discussion of whether it would be feasible to create a new faces scale incorporating everything that has been learned since the original faces scales were developed in the mid-1980s, including data from studies of anatomical facial reactions to pain (44). To create a new ideal faces scale from scratch, using the best available developmental psychology research methods based on the many considerations discussed above, would be expensive but perhaps ultimately worthwhile.

\section{Numerical rating scales}

Although NRS are among the most frequently used selfreport scales (as mentioned above), they are among the least researched in children. Efforts should be made to validate and standardize the scales in ways that are similar to the development of other self-report scales, such as VAS and the FPS-R.

\section{Screening}

As illustrated in Figure 1, the proportion of children who can validly use self-report rating scales increases rapidly from three to seven years of age. This presents an important clinical challenge. A conscientious clinician will want to obtain self-reports from any children who are able to provide them; on the other hand, there is no point in recording self-reports from children who do not understand the scales. There are no well-established methods for identifying young children who can and cannot validly use the scales, although research is underway (40). Pending further research, the safest option is perhaps to assume that, in the absence of contrary evidence, a child eight years of age or older can use NRS; a child seven years of age or older can use VAS; a child five years of age or older can use a faces scale or the Pieces of Hurt tool (13), and a three- or four-year-old should be asked for a quantified selfreport rating only if a parent thinks she or he can respond validly. That set of assumptions will, of course, generate both false positives (invalid scores from children who do not understand the scale) and false negatives (not obtaining valid scores from children who do understand the scale but were not asked).

\section{Training}

Related to the question of screening is the question of whether children who do not understand a self-report scale can be trained to do so. In general, a complex cognitive skill that has not yet been learned cannot be taught in a single quick instruction session; it usually requires practice and structured support from a person who has the skill. Only one study (45) has considered the question of training on self-report scales in detail, and that study used VAS and NRS; other evidence suggests they are not suitable for young children.

\section{Simplified measures for children younger than five years of age}

As outlined above, special considerations apply to self-report scales designed for use by preschool-age children (three to five years of age). A recent report (46) suggests that young children can distinguish only two or three levels in a series of pain faces, but the stimuli in that study were much more similar to each other than faces in typical faces scales, making them more difficult for young children to distinguish. There is a need for research and development of appropriate instructions (in simple language), simplified scales (eg, fewer response options), more distinctive visual features, vertical rather than horizontal presentation, and comprehensible upper verbal and pictorial anchors.

\section{Children with cognitive delay}

Few studies have explored the ability of children with cognitive delay or communication disabilities to use self-report scales (47). Nurses often overestimate the ability of cognitively impaired children to use self-report scales (48). Most studies on assessment of pain in this population rely instead on observational measures. At a minimum, children with mild cognitive impairment should be given a chance to use self-report scales suitable for their mental age.

\section{Knowledge translation and exchange}

Around the world, most children's pain in hospital settings is not managed at all, and when it is managed, it is on the basis of clinicians' hunches and assumptions rather than on data obtained from self-report and observational measures. There is an enormous need for knowledge translation and exchange $(32,49)$. Pain experts can share their knowledge with clinicians in institutions and in countries where best practices are not followed; equally, pain experts can learn from those clinicians about the challenges they face in pain assessment and ways of bringing about improvements at the lowest cost and burden. 


\section{RECOMMENDATIONS FOR CLINICAL PRACTICE}

A number of areas for further research have been identified above. For clinicians treating individual children, the following suggestions are offered.

1. Obtain and record the child's self-report of pain intensity on first contact and at intervals determined by the child's condition. For example, in the US, pain accreditation guidelines (www.jointcommission.org) now set minimum standards for regularity of pain assessments in various inpatient and ambulatory settings.

2. Select a small number of validated, age-appropriate scales for regular use so that they can become familiar to clinicians as well as patients and families. Among the available self-report scales, the author would suggest the use of a faces scale such as the FPS-R (www. painsourcebook.ca) for children four to 12 years of age,

\section{REFERENCES}

1. Franck LS, Greenberg CS, Stevens B. Pain assessment in infants and children. Pediatr Clin North Am 2000;47:487-512.

2. Jordan-Marsh M, Hubbard J, Watson R, Deon Hall R, Miller P, Mohan $\mathrm{O}$. The social ecology of changing pain management: Do I have to cry? J Pediatr Nurs 2004;19:193-203.

3. Craig KD, Badali MA. Introduction to the special series on pain deception and malingering. Clin J Pain 2004;20:377-82.

4. von Baeyer CL, Spagrud LJ. Systematic review of observational (behavioral) measures of pain for children and adolescents aged 3 to 18 years. Pain 2007;127:140-50.

5. Stinson JN, Kavanagh T, Yamada J, Gill N, Stevens B. Systematic review of the psychometric properties, interpretability and feasibility of self-report pain intensity measures for use in clinical trials in children and adolescents. Pain 2006;125:143-57.

6. Blount RL, Loiselle KA. Behavioural assessment of pediatric pain. Pain Res Manage 2009; 14:47-52.

7. von Baeyer CL. Children's self-reports of pain intensity: Scale selection, limitations and interpretation. Pain Res Manage 2006;11:157-62.

8. Bieri D, Reeve RA, Champion GD, Addicoat L, Ziegler JB. The Faces Pain Scale for the self-assessment of the severity of pain experienced by children: Development, initial validation and preliminary investigation for ratio scale properties. Pain 1990;41:139-50.

9. Champion GD, Goodenough B, von Baeyer CL, Thomas W. Measurement of pain by self-report. In: Finley GA, McGrath PJ, eds. Measurement of Pain in Infants and Children. Seattle: IASP Press, 1998:123-60.

10. Hicks CL, von Baeyer CL, Spafford PA, van Korlaar I, Goodenough B. The Faces Pain Scale-Revised: Toward a common metric in pediatric pain measurement. Pain 2001;93:173-83.

11. Wilson D, Hockenberry M, eds. Wong's Clinical Manual of Pediatric Nursing, 7th edn. St Louis: Mosby, 2008.

12. Beyer JE, Denyes MJ, Villarruel AM. The creation, validation, and continuing development of the Oucher: A measure of pain intensity in children. J Pediatr Nurs 1992;7:335-46.

13. Hester NK. The preoperational child's reaction to immunization. Nurs Res 1979;28:250-5.

14. Franck LS, Bruce E. Putting pain assessment into practice: Why is it so painful? Pain Res Manage 2009;14:13-20.

15. Hadjistavropoulos T, Craig KD. A theoretical framework for understanding self-report and observational measures of pain: A communications model. Behav Res Ther 2002;40:551-70.

16. Craig KD. Pain in infants and children: Sociodevelopmental variations on a theme. In: Giamberardino M, ed. Pain 2002 - An updated review. Refresher Course Syllabus. 10th World Congress on Pain. Seattle: IASP Press, 2002:305-14.

17. Manne SL, Jacobsen PB, Redd WH. Assessment of acute pediatric pain: Do child self-report, parent ratings, and nurse ratings measure the same phenomenon? Pain 1992;48:45-52. and 0 to 10 NRS for children eight years of age and older.

3. Recognize that many, but not all, children will be able to use such scales.

4. Complement self-report with observation and knowledge of the context.

5. Take pain scores into account when deciding on pain treatment.

6. In collaboration with the child and parents, establish realistic target pain levels depending on the time and condition.

7. Compare scores across time, not across children.

ACKNOWLEDGEMENT: The author's research is funded by the Canadian Institutes of Health Research. The author thanks David Champion for his contributions to this work.
18. Chambers CT, Johnston C. Developmental differences in children's use of rating scales. J Pediatr Psychol 2002;27:27-36.

19. von Baeyer CL, Forsyth SJ, Stanford EA, Watson M, Chambers CT. Response biases in preschool children's ratings of pain in hypothetical situations. Eur J Pain 2008. (In press)

20. Chambers CT, Craig KD. An intrusive impact of anchors in children's faces pain scales. Pain 1998;78:27-37.

21. Rowbotham MC. What is a "clinically meaningful" reduction in pain? Pain 2001;94:131-2.

22. Powell CV, Kelly AM, Williams A. Determining the minimum clinically significant difference in visual analog pain score for children. Ann Emerg Med 2001;37:28-31.

23. Cepeda M, Carr D. Clinical meaning of a decline in pain intensity in children and its implications in care and research. Pediatr Pain Lett 2006;8:23-7.

24. Barden J, Edwards JE, Mason L, McQuay HJ, Moore RA. Outcomes in acute pain trials: Systematic review of what was reported? Pain 2004;109:351-6.

25. Janicke DM, Finney JW. Empirically supported treatments in pediatric psychology: Recurrent abdominal pain. J Pediatr Psychol 1999;24:115-27.

26. Decruynaere C, Thonnard JL, Plaghki L. Measure of experimental pain using Rasch analysis. Eur J Pain 2007;11:469-74.

27. Savedra MC, Holzemer WL, Tesler MD, Wilkie DJ. Assessment of postoperation pain in children and adolescents using the adolescent pediatric pain tool. Nurs Res 1993;42:5-9.

28. Varni JW, Thompson KL, Hanson V. The Varni/Thompson Pediatric Pain Questionnaire. I. Chronic musculoskeletal pain in juvenile rheumatoid arthritis. Pain 1987;28:27-38.

29. Eland J, Anderson J. The experience of pain in children. In: Jacox A, ed. Pain: A Sourcebook for Nurses and Other Health Professionals. Boston: Little Brown, 1977:453-78.

30. von Baeyer CL, Hicks CL. Support for a common metric for pediatric pain intensity scales. Pain Res Manage 2000;5:157-60.

31. McCaffery M, Pasero C. Pain: Clinical Manual, 2nd edn. St Louis: Mosby, 1999.

32. Finley GA, Forgeron PA. Developing pain services around the world. In: Finley GA, McGrath PJ, Chambers CT, eds. Bringing Pain Relief to Children: Treatment Approaches. Totowa: Humana Press, 2006:177-98.

33. Stinson JN. Improving the assessment of pediatric chronic pain: Harnessing the potential of electronic diaries. Pain Res Manage 2009;14:59-64.

34. Stinson JN, Petroz GC, Tait G, et al. e-Ouch: Usability testing of an electronic chronic pain diary for adolescents with arthritis. Clin J Pain 2006;22:295-305.

35. Stinson JN, Stevens BJ, Feldman BM, et al. Construct validity of a multidimensional electronic pain diary for adolescents with arthritis. Pain 2008;136:281-92. 
36. Falinower S, Martret P, Lombart B, Réti E, Krause D, Annequin D. Auto-évaluation de la douleur aiguë chez l'enfant. Utilisation de l'échelle des visages en version électronique sur micro-ordinateur de poche (PDA) palmOne. Douleurs 2004;5:249-57

37. Fanciullo GJ, Cravero JP, Mudge BO, McHugo GJ, Baird JC. Development of a new computer method to assess children's pain. Pain Med 2007;8(Suppl 3):S121-8.

38. Jensen MP, Karoly P. Self-report scales and procedures for assessing pain in adults. In: Turk DC, Melzack R, eds. Handbook of Pain Assessment, 2nd edn. New York: Guilford Press, 2001:15-34.

39. Wilkinson SR. The Child's World of Illness: The Development of Health and Illness Behaviour. Cambridge (UK): Cambridge University Press, 1988/2006.

40. Besenski LJ, Forsyth SJ, von Baeyer CL. Screening young children for their ability to use self-report pain scales. Pediatr Pain Lett 2007;9:1-6.

41. McGrath PA. Pain in Children: Nature Assessment \& Treatment. New York: Guilford, 1990.

42. Vygotsky LS. Mind in Society: Development of Higher Psychological Processes. Cambridge (USA): Harvard University Press, 1978.

43. von Baeyer CL, Beyer JE, Chambers CT. Putting a new face on faces scales. [Workshop]. The 7th International Symposium on Pediatric Pain. Vancouver, June 25 to 29, 2006.

44. Schiavenato M, Byers JF, Scovanner P, et al. Neonatal pain facial expression: Evaluating the primal face of pain. Pain 2008;138:460-71.

45. Shields BJ, Cohen DM, Harbeck-Weber C, Powers JD, Smith GA. Pediatric pain measurement using a visual analogue scale: $\mathrm{A}$ comparison of two teaching methods. Clin Pediatr (Phila) 2003;42:227-34.

46. Decruynaere C, Thonnard JL, Plaghki L. How many response levels do children distinguish on faces scales for pain assessment? Eur J Pain 2008. (In press)

47. Benini F, Trapanotto M, Gobber D, et al. Evaluating pain induced by venipuncture in pediatric patients with developmental delay. Clin J Pain 2004;20:156-63.

48. Fanurik D, Koh JL, Harrison RD, Conrad TM, Tomerlin C. Pain assessment in children with cognitive impairment. An exploration of self-report skills. Clin Nurs Res 1998;7:103-19; discussion 120-4

49. Finley GA, Franck LS, Grunau RE, von Baeyer CL. Why children's pain matters. International Association for the Study of Pain. Pain: Clinical Updates 2005;13:1-6.

50. Spagrud LJ, Piira T, von Baeyer CL. Children's self-report of pain intensity. Am J Nurs 2003;103:62-4. 


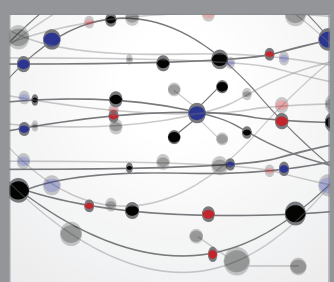

The Scientific World Journal
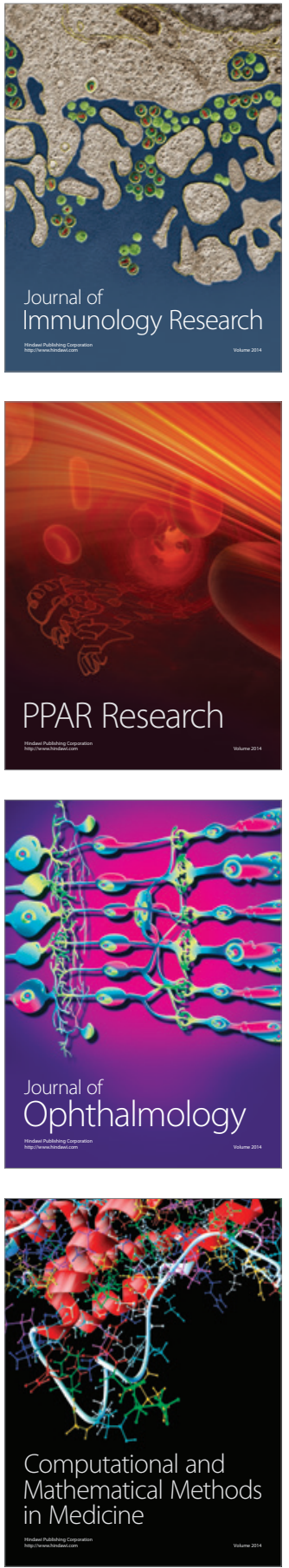

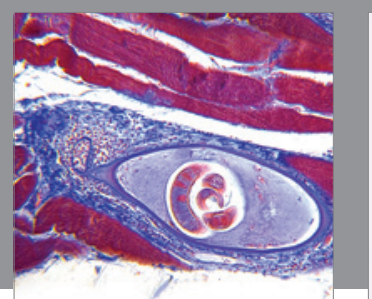

Gastroenterology Research and Practice

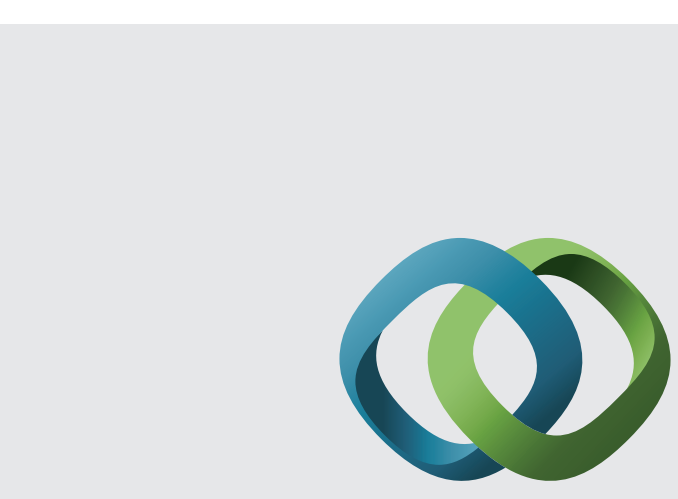

\section{Hindawi}

Submit your manuscripts at

http://www.hindawi.com
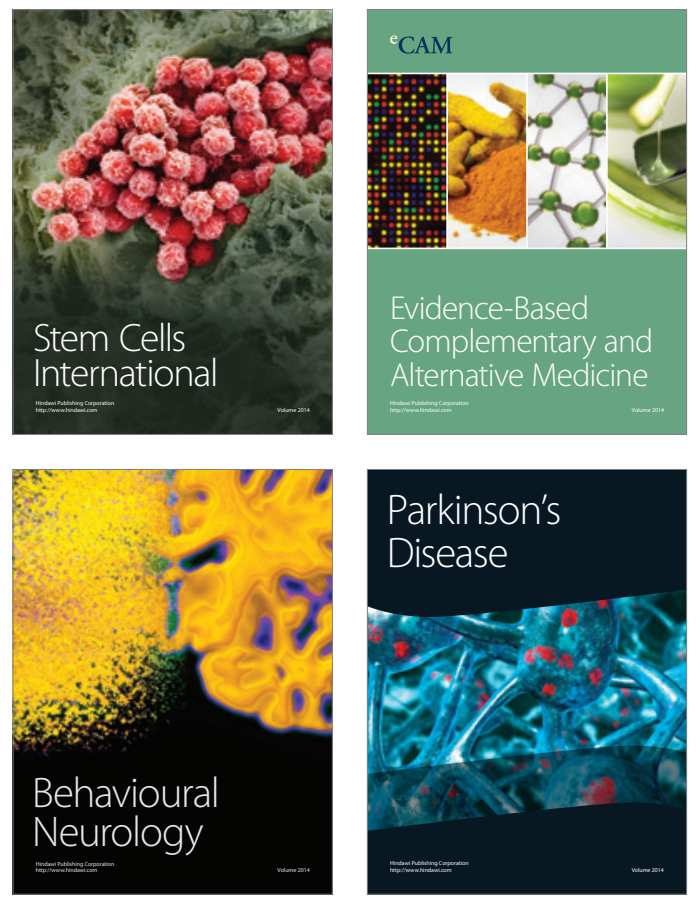
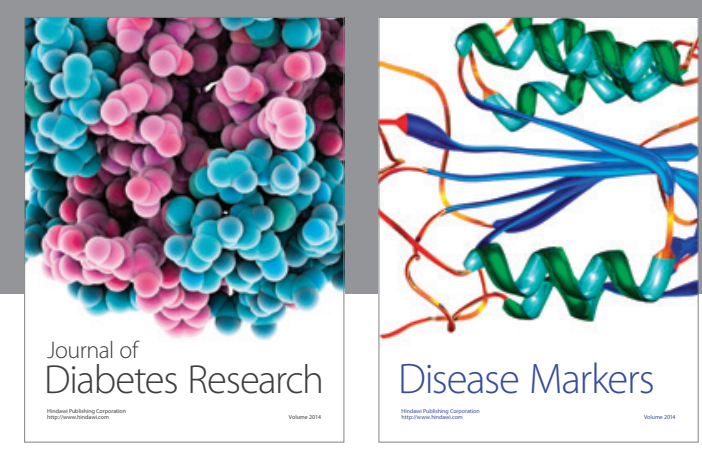

Disease Markers
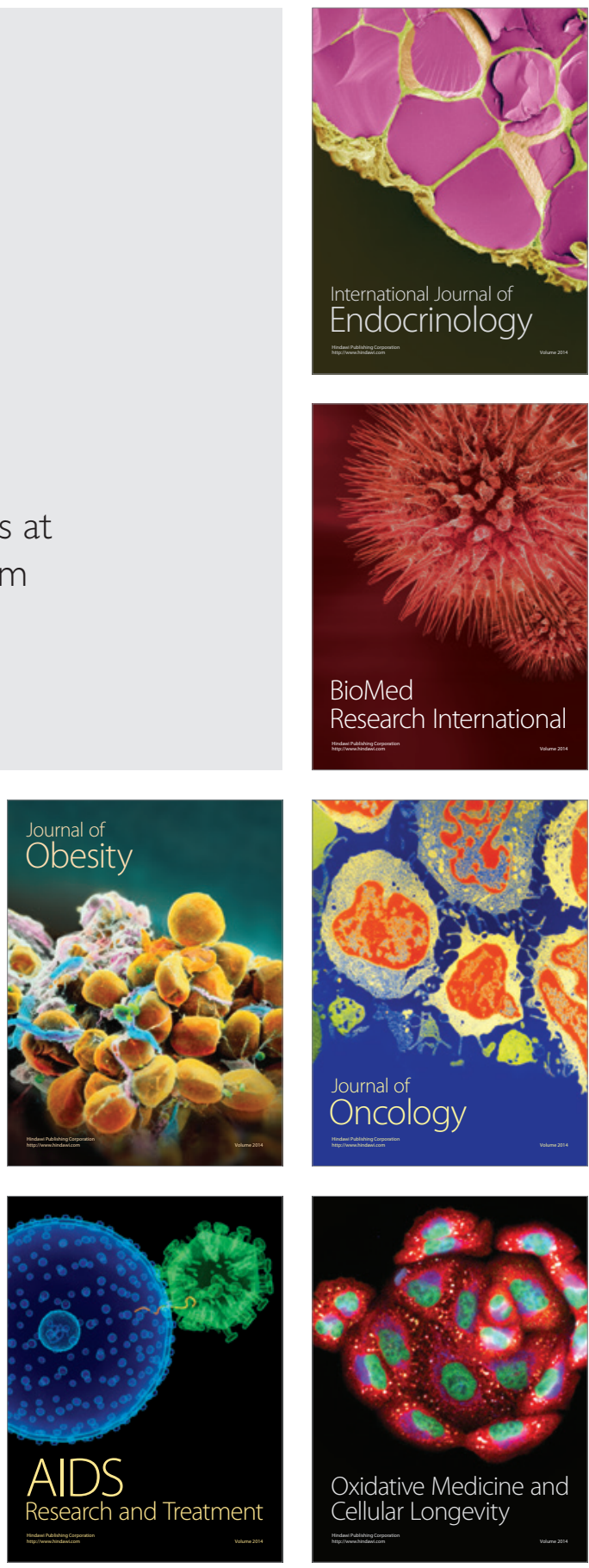